ARTICLE

DOI: $10.1038 / s 41467-018-05802-4$

\title{
Understanding voltage decay in lithium-excess layered cathode materials through oxygen-centred structural arrangement
}

\author{
Seungjun Myeong (10 1, Woongrae Cho (1) 1, Wooyoung Jin (10 1, Jaeseong Hwang ${ }^{1}$, Moonsu Yoon', \\ Youngshin Yoo', Gyutae Nam¹, Haeseong Jang (1) 1, Jung-Gu Han', Nam-Soon Choi', \\ Min Gyu Kim² \& Jaephil Cho'
}

Lithium-excess 3d-transition-metal layered oxides $\left(\mathrm{Li}_{1+x} \mathrm{Ni}_{y} \mathrm{Co}_{z} \mathrm{Mn}_{1-x-y-z} \mathrm{O}_{2},>250 \mathrm{mAh} \mathrm{g}^{-1}\right)$ suffer from severe voltage decay upon cycling, which decreases energy density and hinders further research and development. Nevertheless, the lack of understanding on chemical and structural uniqueness of the material prevents the interpretation of internal degradation chemistry. Here, we discover a fundamental reason of the voltage decay phenomenon by comparing ordered and cation-disordered materials with a combination of X-ray absorption spectroscopy and transmission electron microscopy studies. The cation arrangement determines the transition metal-oxygen covalency and structural reversibility related to voltage decay. The identification of structural arrangement with de-lithiated oxygen-centred octahedron and interactions between octahedrons affecting the oxygen stability and transition metal mobility of layered oxide provides the insight into the degradation chemistry of cathode materials and a way to develop high-energy density electrodes.

\footnotetext{
${ }^{1}$ Department of Energy Engineering and School of Energy and Chemical Engineering, Ulsan National Institute of Science and Technology (UNIST), Ulsan 689798, South Korea. ${ }^{2}$ Beamline Research Division, Pohang Accelerator Laboratory (PAL), Pohang, Kyungbuk 37673, Republic of Korea. Correspondence and requests for materials should be addressed to M.G.K. (email: mgkim@postech.ac.kr) or to J.C. (email: jpcho@unist.ac.kr)
} 
D espite the success of rechargeable lithium-ion batteries in Information Technology (IT) devices, many challenges still remain for large scale energy storage systems such as electric vehicles (EV), especially in terms of high-energy density and low $\operatorname{cost}^{1-3}$. High-capacity Li-excess 3d-transition-metal (3dTM) layered oxides $\left(\mathrm{Li}_{1+x} \mathrm{Mn}_{y} \mathrm{Ni}_{z} \mathrm{Co}_{1-x-y-z} \mathrm{O}_{2}\right)$ are considered as a realistic candidate material for the approaching battery era owing to their high reversible capacities exceeding $250 \mathrm{mAh} \mathrm{g}^{-1}$ and cost competitiveness because of inexpensive manganese ${ }^{4,5}$. Nevertheless, industrial application is challenging due to their poor rate capability and severe discharge voltage decay ${ }^{6-11}$. Among these drawbacks, voltage decay phenomenon, which is not observed in other layered oxides, is an unique and delicate issue for researchers. Previous studies with cation-focused analysis interpreted this phenomenon as 'layered-to-spinel' phase transition and suggested 'surface doping' as a solution for the voltage decay ${ }^{12-25}$. Furthermore, $4 d$ and $5 d$ transition-metal (TM) oxides having a pure $\mathrm{C} 2 / \mathrm{m}$ monoclinic structure, such as $\mathrm{Li}_{2} \mathrm{Ru}_{1-y} \mathrm{M}_{y} \mathrm{O}_{3}(\mathrm{M}=\mathrm{Ti}, \mathrm{Mn}, \mathrm{Sn})$, were introduced to reveal origin of the voltage decay ${ }^{26}$.

However, Li-excess materials with $3 d \mathrm{TM}$ show structural uniqueness $(R \overline{3} m+C 2 / m)$ and no true $\mathrm{O}_{2}{ }^{2-}$ species on oxide oxidation, which is different from those of the heavier TM oxi$\operatorname{des}^{27,28}$. Recent important studies on Li-excess materials mainly focused on elucidating oxygen redox chemistry based on oxygencentred octahedron $\left(\mathrm{M}_{6} \mathrm{O}\right)^{28-30}$. For instance, Ceder et al. suggested a useful participation of new Li-O-Li configuration in the oxygen redox activity for various Li-excess materials. Bruce et al. described electron-hole localization on oxygen surrounded by $\mathrm{Mn}^{4+} / \mathrm{Li}^{+}$cations $\left(\mathrm{O}-\mathrm{Mn}^{4+} / \mathrm{Li}^{+}\right)$to explain the oxygen chemistry in $\mathrm{Li}_{1.2} \mathrm{Ni}_{0.13} \mathrm{Co}_{0.13} \mathrm{Mn}_{0.54} \mathrm{O}_{2}$. Despite such a reasonable local structural approaches, the voltage decay phenomenon can be still open issue, owing to a lack of consideration for long-range arrangement of de-lithiated $\mathrm{M}_{6} \mathrm{O}(\mathrm{M}=$ transition metal or $\mathrm{Li}$ cation) octahedron and interactions affecting the overall oxygen stability. Therefore, multilateral and macroscopic analysis reflecting oxygen characteristics in a long-range structural arrangement is required to understand the voltage decay.

In this study, we focus on ordered and cation-disordered $\mathrm{Li}^{-}$ excess $3 d \mathrm{TM}$ layered oxides showing significantly different degree of voltage decay. Operando atomic-selective X-ray absorption spectroscopic (XAS) analysis was conducted by synchronizing with $\mathrm{dQ} / \mathrm{dV}$ plots to obtain a direct evidence of the voltage decay phenomenon. By combining spectroscopic and microscopic techniques, we observed the different gradation in TM-O covalency and atomic rearrangement considering structural uniqueness. Furthermore, different variation in specific TM-O bonding and TM ion migration depending on cycles, which can be a crucial parameter determining the degree of voltage decay, were revealed during cycling. Furthermore, we identify long-range structural arrangement with three types of de-lithiated oxygencentred octahedron $\left(\mathrm{M}_{4} \mathrm{O}\right)$ to discover a fundamental reason how atomic arrangement affects structural stability of Li-excess $3 d \mathrm{TM}$ layered oxides and the degree of voltage decay.

\section{Results}

Voltage decay phenomenon during cycling. The Li-excess $3 d \mathrm{TM}$ layered oxides with different TM compositions, ${ }^{\prime} \mathrm{Li}_{1.15} \mathrm{Mn}_{0.51} \mathrm{Co}_{0.17} \mathrm{Ni}_{0.17} \mathrm{O}_{2}$ composition with well-ordered layered phase and long-range ordered Li-TM-TM arrangement (denoted as O-MNC) and $\mathrm{Li}_{1.09} \mathrm{Mn}_{0.55} \mathrm{Ni}_{0.32} \mathrm{Co}_{0.043} \mathrm{O}_{2}$ composition with cation-disordered layered phase and short-range ordered Li-TM-TM arrangement (denoted as D-MNC) were prepared by co-precipitation method. Morphology and crystal structure were confirmed by scanning electron microscopy (SEM) and X-ray diffraction (XRD) (Supplementary Figs. 1 and 2). Furthermore, crystallographic parameters for O-MNC and DMNC were obtained by Rietveld refinement (Supplementary Tables 1 and 2) and discussion in Supplementary Note 1. The results indicate that $\sim 3$ times more $\mathrm{Ni}$ and $\mathrm{Co}$ ions have occupied the Li site in D-MNC (total $0.10 \mathrm{~mol}$ ) compared to O-MNC (total $0.03 \mathrm{~mol}$ ). O-MNC and D-MNC show initial discharge capacities over $250 \mathrm{mAh} \mathrm{g}^{-1}$ with coulombic efficiency over $90 \%$. For an exact comparison of voltage decay, we considered the 1st cycle reversible capacity because the amount of extracted lithium ion from the cathode material is directly related to structural degradation, and thus, voltage decay. Long-term cycling test of $\mathrm{O}$ MNC were conducted with two different voltage cutoff conditions, $2.00-4.35 \mathrm{~V}$ (denoted as OL-MNC) and $2.00-4.60 \mathrm{~V}$ (denoted as $\mathrm{OH}-\mathrm{MNC}$ ) with $0.5 \mathrm{C}$ and $1.0 \mathrm{C}$ charge and discharge $\mathrm{C}$-rates, respectively. Thereafter, we confirmed the discharge capacity from the 1 st cycle: $150 \mathrm{mAh} \mathrm{g}^{-1}$ for OL-MNC and 200 $\mathrm{mAh} \mathrm{g}^{-1}$ for OH-MNC. In addition, the D-MNC half-cell exhibited $200 \mathrm{mAh} \mathrm{g}^{-1}$ at the 1st cycle in the voltage window of 2.00-4.60 V. All samples showed capacity retention of almost 93 $\%$ after 100 cycles (Supplementary Fig. 3 and Supplementary Table 3). The coloured regions in Fig. 1a, b show the difference in the degree of voltage decay from the 10th to 100th cycle for samples. Voltage decay was observed in both on charge and discharge process. The average discharge voltages of OL-MNC and $\mathrm{OH}-\mathrm{MNC}$ decreased by $31.6 \mathrm{mV}$ and $317.0 \mathrm{mV}$ during cycling, respectively (Fig. 1a); however, D-MNC shows only 56.0 $\mathrm{mV}$ of voltage decay (Fig. $1 \mathrm{~b}$ and Supplementary Table 4). This tendency is definitely recognized with $\mathrm{dQ} / \mathrm{dV}$ plots shown in Fig. 1c. OH-MNC significantly exhibited both a disappearance of reduction peak at around $3.70 \mathrm{~V}$ and the new development of reduction peak at around $2.80 \mathrm{~V}$ during cycling, while OL-MNC retained its original profile even after 100th cycle. In case of D$\mathrm{MNC}$, the overall change in reduction peaks is suppressed despite the same electrochemical testing condition with $\mathrm{OH}-\mathrm{MNC}$.

Comparison of redox mechanism variation. In order to elucidate the different redox reactions observed in $\mathrm{d} Q / \mathrm{d} V$ plot during cycling, operando $\mathrm{Mn}, \mathrm{Ni}$, and Co K-edges X-ray absorption near edge structure (XANES) spectra were collected for the 10th and 100th electrodes using the on-the-fly scan mode under the same electrochemical test condition above (Fig. 2a-d). The oxidation states of TMs in initial, charged, and discharged states at the 10th and 100th cycle were obtained from least-square method (Supplementary Fig. 4-6 and Supplementary Table 5) ${ }^{31,32}$. At the 10th cycle, $\mathrm{OH}-\mathrm{MNC}$ shows a wide variation range of oxidation state $(\Delta \mathrm{Ox})$ and reduction state $(\Delta \mathrm{Red})$ towards higher oxidation states at the charged state due to a high cutoff voltage $\left(\mathrm{Mn}^{3.65+} / \mathrm{Ni}^{3.08}\right.$ $\left.+/ \mathrm{Co}^{2.98+}\right)$. In particularly, irreversible redox behaviour is observed at $\mathrm{Mn}$ state $(\Delta \mathrm{Ox}: 0.46 / \Delta \mathrm{Red}: 0.35)$. This contrasts with the redox reactions of $\mathrm{D}-\mathrm{MNC}$, which resulted in narrow $\Delta \mathrm{Ox} /$ $\Delta$ Red, lower oxidation states $\left(\mathrm{Mn}^{3.53+} / \mathrm{Ni}^{2.88+} / \mathrm{Co}^{2.85+}\right)$, and relatively reversible $\mathrm{Mn}$ redox ( $\Delta \mathrm{O} x$ : $0.34 / \Delta \mathrm{Red}: 0.29)$. This feature indicates that charged TM ion in D-MNC form a relatively covalent bond with surrounded oxygen compare to $\mathrm{OH}-\mathrm{MNC}$ because low oxidation number in TM ion is arisen from existence of numbers of shared electrons in TM-O bonding. During the 100th cycle, wider $\Delta \mathrm{Ox} / \Delta$ Red was commonly observed in all TMs of D-MNC however, almost same oxidation states of $\mathrm{Mn}$ ion at 100th charged states with 10th charged states were observed in both OH-MNC and D-MNC.

In order to elucidate real-time redox reaction depending on the voltage decay during 10th and 100th cycle, differentiated XANES spectra $\left(X_{\mathrm{i}}-X_{\text {pristine }}\right)$ were presented with 2D-contour map by synchronizing with $d Q / d V$ plots in Fig. 2a-d and Supplementary 

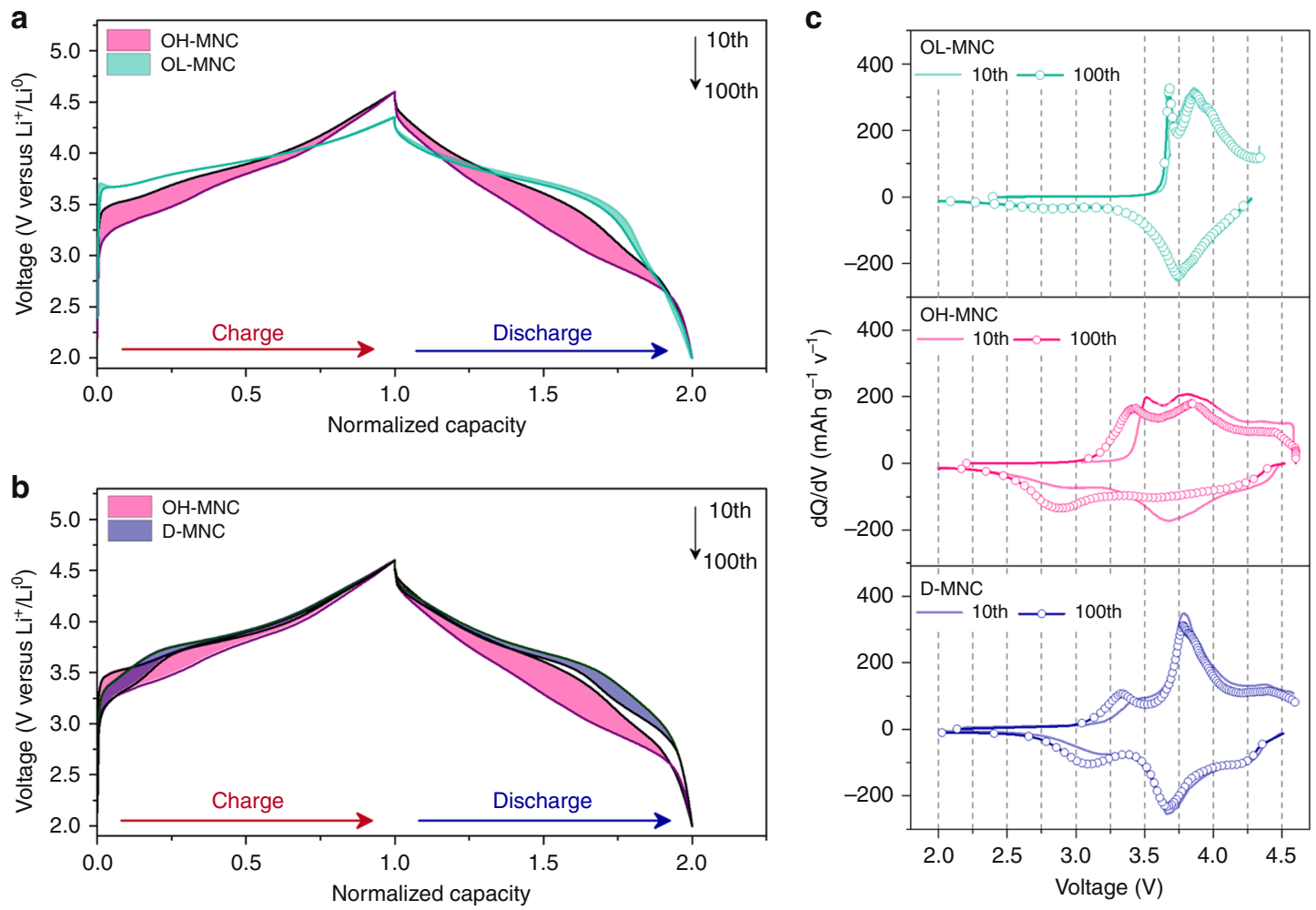

Fig. 1 Cycle behaviuor of O-MNC and D-MNC with a view towards voltage decay. Normalized voltage profile variation for O-MNC and D-MNC from 10th to 100 th cycles; Voltage profile variation of $\mathbf{a} \mathrm{O}-\mathrm{MNC}$ in the $2.00-4.35 \mathrm{~V}$ and $2.00-4.60 \mathrm{~V}$ (vs. Li-metal) potential region. $\mathbf{b} \mathrm{O}-\mathrm{MNC}$ and D-MNC in the 2.00-4.60 V (vs. Li-metal) potential region; $0.5 \mathrm{C}$-rate charge $1.0 \mathrm{C}$-rate discharge condition. The capacity normalization was performed by taking the maximum capacity in the corresponding cycle as unity. $\mathbf{c} \mathrm{dQ} / \mathrm{dV}$ plots for the O-MNC and D-MNC obtained from voltage profiles in $\mathbf{a}, \mathbf{b}$

Fig. 7. In the crossline intensities of each peak during the 10th cycle, Mn K-edge XANES of OH-MNC is significantly more irreversible than that of D-MNC (Fig. 2e, f), while reversible behaviour of $\mathrm{Ni}$ and $\mathrm{Co}$ is observed in both $\mathrm{OH}-\mathrm{MNC}$ and $\mathrm{D}$ MNC (Supplementary Figs. 8 and 9).

During the 100th cycle, D-MNC not only retains the overall patterns of TM K-edges, but also shows more solidified peak features (Fig. 2d). However, the 100th OH-MNC shows different 2D contour map pattern from 10th cycle (Fig. 2c) in which overall peak intensity of patterns are gradually diminished at $\mathrm{Ni}$ and Co K-edge. Furthermore, Mn K-edge of 100th cycle shows very different overall peak features contrast to that of 10 th cycle. In the 100th charge process of OH-MNC, the suppressed oxidation reaction of $\mathrm{Ni}$ and $\mathrm{Co}$ starts at higher voltage and the active oxidation reaction of $\mathrm{Mn}$ occurs at lower voltage compared with D-MNC in the 100th charging process, which are well matched with the tendency of $\mathrm{dQ} / \mathrm{dV}$ plot. Consequently, it can be expected that the structural instability associated with irreversible $\mathrm{Mn}$ ion redox at 10th cycle is a critical factor causing the abnormal behaviour in redox activities of the $\mathrm{Ni} / \mathrm{Co}$ and $\mathrm{Mn}$ ions during cycling, resulting in the noticeable peak decrease at around $3.70 \mathrm{~V}$ and peak increase at around $2.80 \mathrm{~V}$ in $\mathrm{dQ} / \mathrm{dV}$ plot.

Electronic structure of TM-O bonding. The electron-hole state in TM-O bonding is closely related to structural stability, resulting in TM redox activity variation; thus, scanning transmission X-ray microscopy (STXM) was performed to reveal the oxygen state in materials, which undergo both TM and oxygen redox during electrochemical reactions. Figure $3 a-c$ shows the $O$ K-edge soft X-ray absorption spectroscopy (Soft-XAS) data of free standing pristine and 10th and 100th cycled (discharged state) OL-MNC, OH-MNC, and D-MNC single particles chosen by microscopy imaging (Supplementary Fig. 10). Firstly, the broad main peak of the O K-edge spectra above $534.0 \mathrm{eV}$ corresponds to transition from $\mathrm{O} 1 s$ to the hybridized state of $\mathrm{O} 2 p$ and TM4sp orbitals. Secondly, the shaded area below $534.0 \mathrm{eV}$ in Fig. 3 indicates the hybridized state of $\mathrm{O} 2 p$ and TM $3 d$ orbitals $(\mathrm{O} 2 p-\mathrm{TM} 3 d)$. The distinct doublet peak feature in the pre-edge region (peak A at $\sim 529.5 \mathrm{eV}$ and peak $\mathrm{B} \sim 531.0 \mathrm{eV}$ ) are associated with the transition of O1s electron to the hybridized state of $\mathrm{O} 2 p$ with TM $3 d t_{2 \mathrm{~g}}$ and TM3de $e_{\mathrm{g}}$ states, respectively $28,33,34$.

The intensity of peak $\mathrm{A}$ in the pristine $\mathrm{O}-\mathrm{MNC}$ is remarkably lower than that in $\mathrm{D}-\mathrm{MNC}^{35}$, implying that the electrons originating from oxygen vacancy $\left(\mathrm{O}_{\mathrm{O}}=\mathrm{V}^{\prime \prime} \mathrm{O}+2 \mathrm{e}^{-}+0.5 \mathrm{O}_{2}\right)$ occupy the TM $3 d t_{2 \mathrm{~g}}$ states. Therefore, higher intensity in D-MNC means more covalent interaction on $\mathrm{O} 2 p-\mathrm{TM} 3 d t_{2 \mathrm{~g}}$ hybridized orbital (Hybridization is a model that modifies atomic orbitals to explain the covalent bonding phenomenon 'covalancy'). After the 10th and 100th cycles, the integrated intensity of the pre-edge peak (area of the shaded region in Fig. 3a), which is directly related to the degree of TM-O covalency, gradually decreased by $\sim 0.82 / \sim 2.62 \%$ for OL-MNC and dramatically decreased by $\sim 3.54 /$ $\sim 16.22 \%$ for OH-MNC. In contrast, D-MNC still shows obvious pre-edge peaks, whose intensities gradually decrease by $\sim 2.46 /$

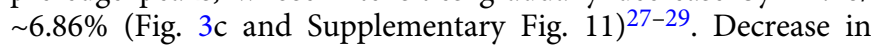
integrated intensity of the pre-edge peak until 10th and 100th cycle is dominantly correlated with activation of $\mathrm{Li}_{2} \mathrm{MnO}_{3}$ accompanying oxygen loss and overall structural degradation, respectively. TM-O hybridization and oxygen evolving due to surface reactions are very relevant. By comparing the Bet surface area of both pristine D-MNC and O-MNC, D-MNC $\left(5.08 \mathrm{~m}^{2} \mathrm{~g}^{-1}\right)$ has a higher area than O-MNC $\left(3.36 \mathrm{~m}^{2} \mathrm{~g}^{-1}\right)$. This implies that 
$\mathrm{OH}-\mathrm{MNC}$ - 10th

a

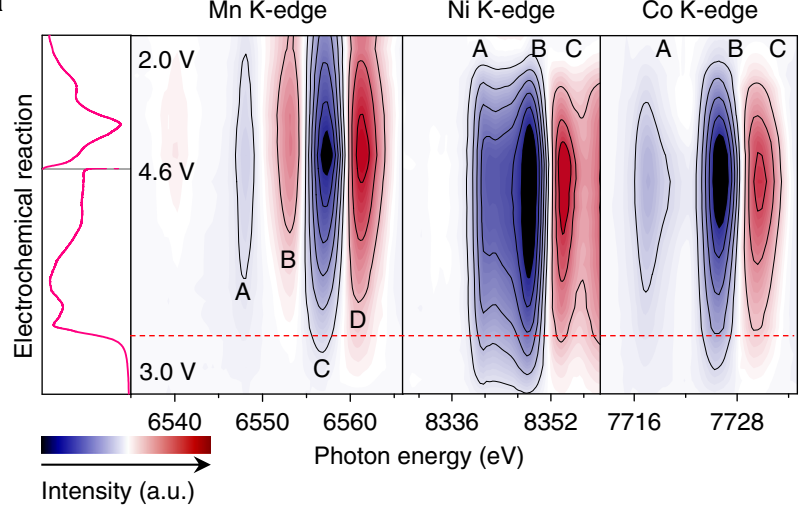

OH-MNC - 100th

C

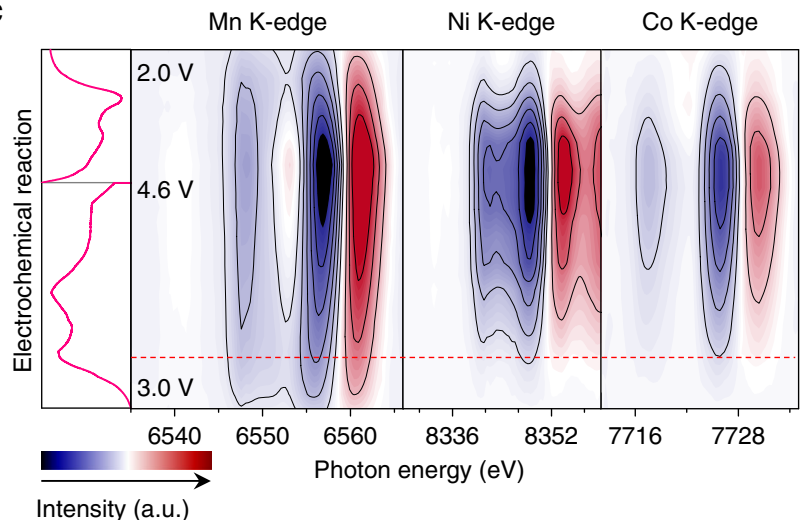

e

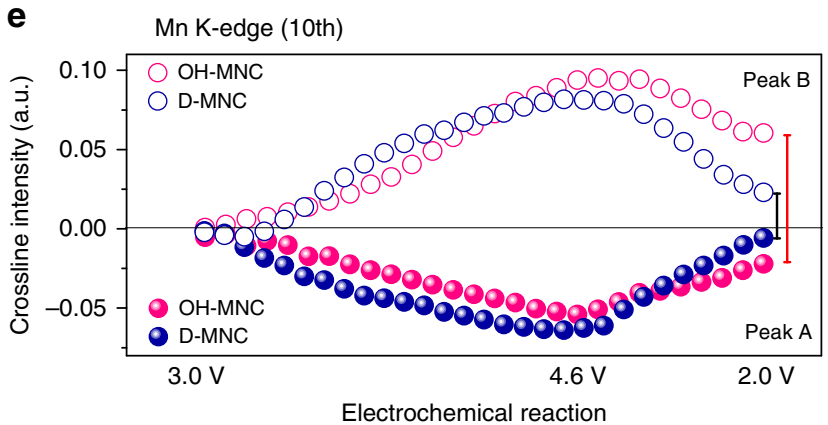

D-MNC - 10th

b

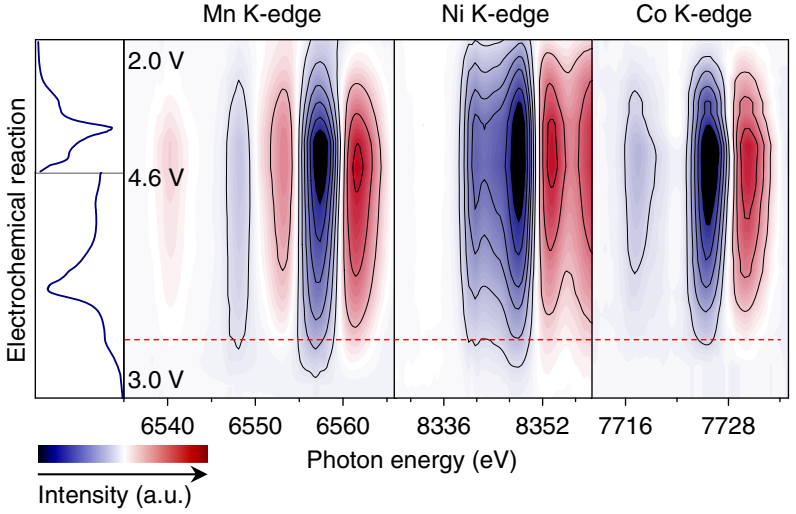

D-MNC - 100th

d

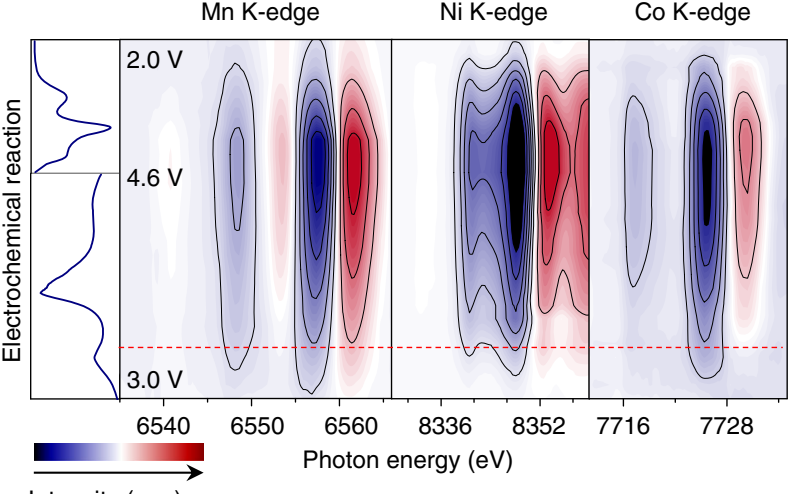

Intensity (a.u.)

f

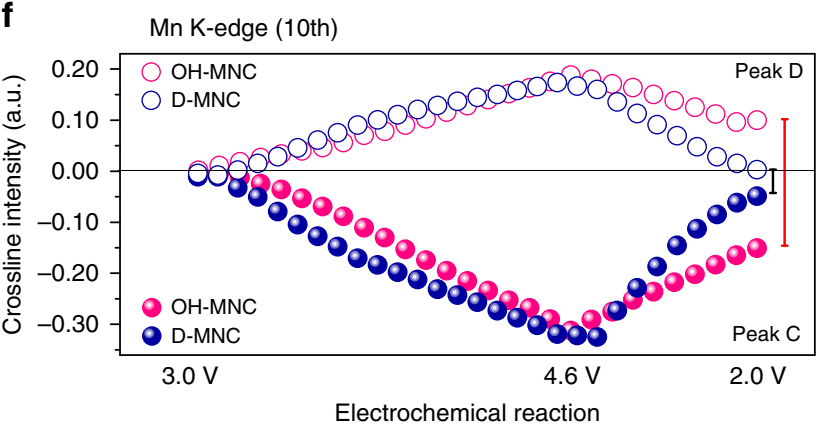

Fig. 2 Transition-metal K-edge operando XANES variation during cycling. Mn, Ni, and Co K-edge operando XANES spectra (2D contour plot) and voltage profiles of a OH-MNC 10, b D-MNC 10th, c OH-MNC 100th, and d D-MNC 100th; Crossline intensity of Mn K-edge operando XANES spectra peaks e A and $\mathrm{B} ; \mathbf{f} \mathrm{C}$ and $\mathrm{D}$ during 10 th cycle; Electrodes were cycled at $0.5 \mathrm{C}$-rate charge $1.0 \mathrm{C}$-rate discharge condition

the more surface reaction proceeds compared to O-MNC when the reactivity of the materials is assumed to be the same. However, structural stability and $\mathrm{O}$ K-edge change in D-MNC were less and more stable compared to $\mathrm{OH}-\mathrm{MNC}$. This suggests that the hybridization feature of TM-O contributes a lot to surface reactivity as well as structural stability. Therefore, surface reaction is highly relevant with TM-O hybridization.

On oxidation (lithium extraction) of OH-MNC and D-MNC, electrons are removed from the TM orbital and electron transfer from the $\mathrm{O} 2 p$ band to the TM band occurs to compensate charge neutrality with hole creation in the $\mathrm{O} 2 p$ band ${ }^{33,34}$. Therefore, repeated charge-discharge process with high voltage condition leads to excessive hole creation in the $\mathrm{O} 2 p$ orbital and labile oxygen state. Consequently, the conservation of pre-edge peak intensities in D-MNC after 10th and 100th cycle means that the covalent bonding character of O-3dTM loses less oxygen from the lattice during cycling even at a high voltage, which originated from more covalent and high possibility of hole-delocalization on $\mathrm{Mn}^{3.53+}-\mathrm{O}$ bonding in contrast to $\mathrm{Mn}^{3.65+}-\mathrm{O}$ bonding of $\mathrm{OH}$ MNC (Fig. 3d).

Microscopy atomic arrangement analysis. A combination of high-angle annular dark-field scanning transmission electron microscopy (HAADF-STEM) and energy dispersive X-ray spectroscopy (EDS) reveals the correlation between oxygen stability and structural arrangement. Delmas et al, successfully investigate the structural rearrangement of $1^{\text {st }}$ cycled Li-excess $3 \mathrm{dTM}$ material along $[100]_{\text {mono }}$ zone axis $^{36}$. In order to analyze the structural characteristic of Li-excess material correctly, Atomic arrangement along $[100]_{\text {mono }}$ direction where we can observe 

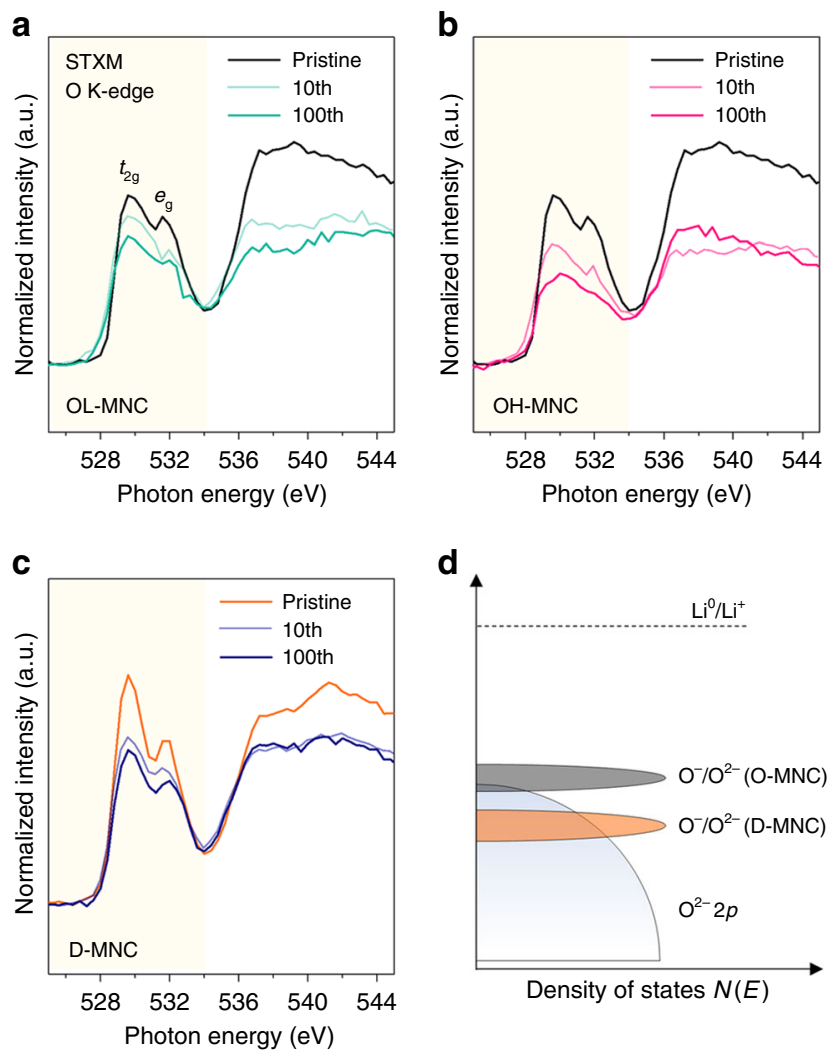

Fig. 3 Oxygen stability of TM-O bonding and electron hole localization on oxygen. Oxygen K-edge SXAS spectrum of $\mathbf{a} \mathrm{OL}-\mathrm{MNC} \mathbf{b} \mathrm{OH}-\mathrm{MNC} \mathbf{c} \mathrm{D}-$ MNC; the spectra collected on Pristine, 10th cycled and 100th cycled (discharged state) particle. $\mathbf{d}$ Schematic diagram of the possible $\mathrm{O}^{-} / \mathrm{O}^{2-}$ redox couple position based on TM-O covalency

$\mathrm{Li}_{2} \mathrm{MnO}_{3}$ phase is additionally needed to increase the structural analysis accuracy. Therefore, we observed that structural deterioration from the layered to the spinel phase occurs in both directions through not only the $[310]_{\text {mono }}$ zone but also the distinguishable $[100]_{\text {mono }}$ zone. Through the EDS analysis, sequence of structural deterioration associated with oxygen deficiency were proposed. Pristine O-MNC features a well-ordered layered structure without cation disordering within the Li layer along the $[100]_{\text {mono }}$ and $[310]_{\text {mono }}$ directions. Both TM-TM-TM arrangement of $\mathrm{LiTMO}_{2}$ structure and Li-TM-TM of the $\mathrm{Li}_{2} \mathrm{TMO}_{3}$ structure coexisted in O-MNC along the $[100]_{\text {mono }}$ direction. Additionally, a spot-streak in the FFT pattern of pristine O-MNC resulting from the coexistence of $\mathrm{Li}_{2} \mathrm{TMO}_{3}$ structure along $[100]_{\text {mono }},[\overline{1} \overline{1} 0]_{\text {mono }}$, and $[\overline{1} 10]_{\text {mono }}$ indicates stacking faults in $\mathrm{O}-\mathrm{MNC}^{37}$. In contrast, cation disordering within the $\mathrm{Li}$ layer were observed in pristine D-MNC along $[310]_{\text {mono }}$ and $[100]_{\text {mono }}$ directions (Fig. 4a, b and Supplementary Fig. 12) ${ }^{37-41}$.

After 100 cycles, OH-MNC (discharged state) shows severe phase transition along both $[310]_{\text {mono }}$ and $[100]_{\text {mono }}$ directions, originating from cation migration between octahedral sites within the TM ( $\mathrm{LiTMO}_{2}$ phase) / $\mathrm{LiTM}\left(\mathrm{Li}_{2} \mathrm{TMO}_{3}\right.$ phase) layers and $\mathrm{Li}$ layers (denoted as $\mathrm{O}_{\mathrm{TM}}, \mathrm{O}_{\mathrm{LiTM}}$, and $\mathrm{O}_{\mathrm{Li}}$ ) (Fig. 4c, d). Migration of cations from $\mathrm{O}_{\mathrm{TM}}$ and $\mathrm{O}_{\mathrm{LiTM}}$ to $\mathrm{O}_{\mathrm{Li}}$ causes propagation of Domain $\mathrm{B}\left(\mathrm{LiTM}_{3} \mathrm{O}_{4}\right.$ phase) into the internal structure during cycling. Continuous $\mathrm{Li}$ intercalation and oxygen loss leads to additional cation migration from octahedral site to tetrahedral site, resulting in Domain $\mathrm{A}\left(\mathrm{TM}_{3} \mathrm{O}_{4}\right.$ phase) at the outer surface of $\mathrm{OH}-\mathrm{MNC}$ which directly contacted with electrolyte (Supplementary Fig. 13 and 14). These structures match well with the simulated HAADF/ABF-STEM image of I41 structure model along both $[310]_{\text {mono }}$ and $[100]_{\text {mono }}$ directions.

Interestingly, the cation-disordered structure of D-MNC (discharged state) is preserved without further phase transition even after 100 cycles compared to OH-MNC (Fig. 4c, d and Supplementary Fig. 15). Furthermore, EDS analysis reveals the oxygen deficiency according to the distance from the outer surface (Supplementary Fig. 16, 17 and Supplementary Table 6). $\mathrm{O} / \mathrm{TM}$ ratio below 1.33 indicating $\mathrm{TM}_{3} \mathrm{O}_{4}$ phase was detected at a distance of $\sim 23 \mathrm{~nm}$ from the surface of OH-MNC and within $\sim 5$ $\mathrm{nm}$ for D-MNC, consistent with the results of STXM. Continuous oxygen loss and consequent cation migration $\left(\mathrm{O}_{\mathrm{TM}} / \mathrm{O}_{\mathrm{LiTM}} \rightarrow \mathrm{O}_{\mathrm{Li}} \rightarrow\right.$ tetrahedral site) resulting in a three-step phase transition (Layered $\rightarrow \mathrm{LiTM}_{3} \mathrm{O}_{4}$ phase $\rightarrow \mathrm{TM}_{3} \mathrm{O}_{4}$ phase) in both $[310]_{\text {mono }}$ and $[100]_{\text {mono }}$ directions (Supplementary Fig. 18 and Supplementary Note 2).

Atomic-selective structural analysis. In order to reveal the relationship between atomic rearrangement and TM redox mechanism changes on prolonged cycling, XRD profiles and extended X-ray absorption fine structure (EXAFS) spectra were investigated. The XRD patterns of OL-MNC, OH-MNC, and DMNC show significant peak shifts towards lower angles and the super-lattice peak disappears from their XRD profiles after 10 cycles. However, even if severe voltage decay is occurred in $\mathrm{OH}$ MNC during 100 cycles, a slight peak shift towards lower angles is observed (Supplementary Fig. 19). Although the XRD profiles reveal the expansion of lattice, they do not indicate mutual atomic arrangements and local atomic transitions around the specific TM related to voltage decay.

The radial distribution function (RDF) of the $\mathrm{Mn}, \mathrm{Ni}$, and $\mathrm{Co}$ K-edge $k^{3} \chi(k)$ EXAFS spectra providing local structure of a specific TM element was investigated and the interatomic distance was quantitatively analysed. Additionally, correlations between spectra peaks and structural information are schematically described in Supplementary Fig. 20. Interestingly, the lower TM-A/C peak and higher TM-B peak were observed in pristine $\mathrm{D}-\mathrm{MNC}$ than those of pristine O-MNC. This indicates that the pristine $\mathrm{D}$-MNC structure has a relatively disordered arrangement in the TM and Li layer than the pristine O-MNC structure does (Supplementary Fig. 21). After the 100th cycle, a significant decrease in $\mathrm{Mn}-\mathrm{O}$ and $\mathrm{Ni} / \mathrm{Co}-\mathrm{TM}$ peaks were observed in 100thcycled OH-MNC (discharged state) compared with the OL-MNC (Fig. 5a and Supplementary Fig. 22), which originated from irreversible $\mathrm{Ni} / \mathrm{Co}$ ion migration (intra-layer to $\mathrm{O}_{\mathrm{Li}}$ in the interlayer) and evolution of layered $\mathrm{MnO}_{2}$-type structure caused by lithium extraction and oxygen loss from $\mathrm{Li}_{2} \mathrm{MnO}_{3}$ and $\mathrm{LiTMO}_{2}$ phases ${ }^{11,42-45}$. In contrast, overall peak features in all RDFs for D-MNC (discharged state) were relatively constant, compared with $\mathrm{OH}-\mathrm{MNC}$, indicating the relative preservation of TM local structure surrounded by oxygen and TM even during 100th cycle.

In order to investigate real-time structural variation and consequent atomic rearrangement after 10th and 100th cycle, the RDFs of TM-O and TM-A K-edge peak at all TM were plotted with a $2 \mathrm{D}$ contour map as a function of electrochemical reaction for clarity (Fig. 5b, c). During the charge-discharge, the $2 \mathrm{D}$ pattern intensities for each bonding pair in D-MNC keep a constant feature or become more intense from 10th to 100th cycle, while $\mathrm{OH}-\mathrm{MNC}$ at 100th cycle distinctly shows a significant decrease in pattern intensity compared to $\mathrm{OH}-\mathrm{MNC}$ at 10 th cycle. The diminishing intensities in OH-MNC from 10th to 100th cycle indicate more oxygen loss from the lattice, less covalent bonding, and a static disorder of edge-shared TM coordination (ordered-to-disordered phase transition). On the other hand, the constant intensity of D-MNC for both 10th and 
a

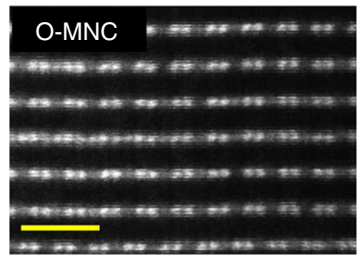

$\odot[100]$ mono

b

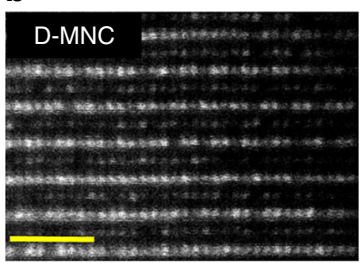

$\odot[100]$ mono
C

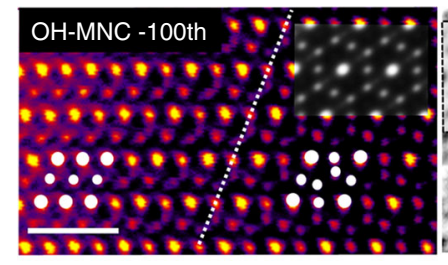

$\odot[310]$ mono $\longrightarrow$ Outer

d

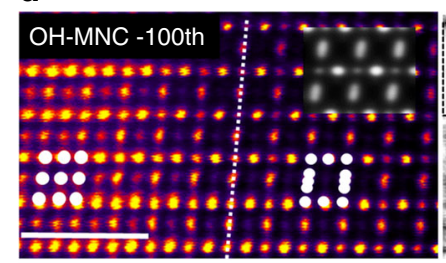

$\odot[100]$ mono

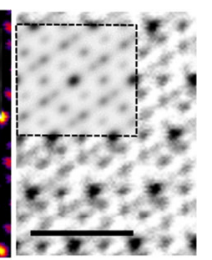

$+2+2 \geqslant 3$

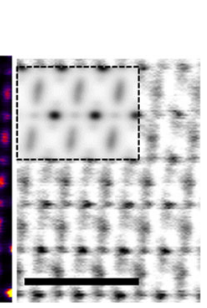

e

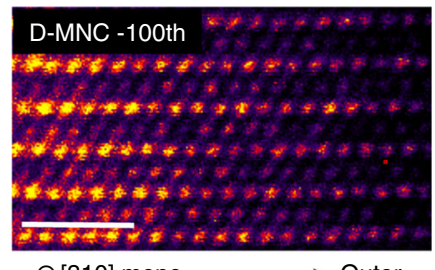

$\odot[310]$ mono $\longrightarrow$ Outer

f

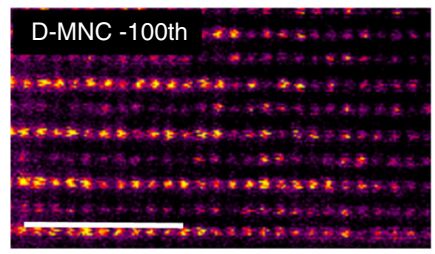

$\odot[100]$ mono $\longrightarrow$ Outer

Fig. 4 Evolution of atomic structure. HAADF-STEM image of the $\mathbf{a}[100]_{\text {mono }}$ Pristine O-MNC, $\mathbf{b}[100]_{\text {mono }}$ Pristine D-MNC particle. $\mathbf{c}[310]_{\text {mono }}$ OH-MNC, d $[100]_{\text {mono }} \mathrm{OH}-\mathrm{MNC}$, e [310] $]_{\text {mono }}$ D-MNC and $\mathbf{f}[100]_{\text {mono }}$ D-MNC particle (discharged state) after 100 charge-discharge cycles. Enlarged HAADF/ABFSTEM images of the surface region in images $\mathbf{c}$ and $\mathbf{d}$ with simulate HAADF/ABF-STEM images (in the inset) are presented; Scale bar denotes $1 \mathrm{~nm}$

$100^{\text {th }}$ cycle reflects less oxygen loss from lattice and low possibility of cation disordering (disordered-to-disordered). Considering the RDFs, Soft-XAS, and XANES data in Fig. 2, we conclude that the stability of $\mathrm{Mn}-\mathrm{O}$ bonding in Li-excessed $3 d \mathrm{TM}$ layered oxides is highly correlated with the overall reversibility of TM-O and immobilization of TM ion during cycling. The change in the redox reaction of a material is related to the oxidation number of the TM that constitutes the material, and the change in the oxidation number is closely related to the structural change.

The $\mathrm{OH}-\mathrm{MNC}$, which has a relatively higher oxidation number in the 10th charged state, has fewer shared electron between TM and $\mathrm{O}$ resulting in a weak covalent TM-O bond. Therefore, the higher the oxidation number in the charged state, the more unstable TM-O bonding will result in a structurally unstable state. Covalent bond of $\mathrm{Mn}-\mathrm{O}$ bonding which is the main structure of the Li-excess $3 d \mathrm{TM}$ oxide materials, is weakened due to the excessive delithiation/charge process for high capacity expression resulting in the labile oxygen release with oxygen vacancy formation in structure resulting in hole generation during the 10 th cycle. Electrons originating from oxygen vacancy $\left(\mathrm{O}_{\mathrm{O}}=\right.$ $\mathrm{V}{ }_{\mathrm{O}}+2 \mathrm{e}^{-}+0.5 \mathrm{O}_{2}$ ) occupy the $\mathrm{TM} 3 d t_{2 \mathrm{~g}}$ states resulting in reversible hole decrease of $\mathrm{Mn}$ ion. As a result, the $\mathrm{Mn}$ ions with hole, which can reversibly receive the electrons, are more in DMNC by exhibiting reversible characteristics which originated from gradual increase (decrease) in hole (TM-O covalancy) during 10th cycle compared to $\mathrm{OH}-\mathrm{MNC}$. When undergoing a long-term charge/discharge process, continuous unstable $\mathrm{Mn}-\mathrm{O}$ bond formation and existence of oxygen vacancies cause unstable structure sequentially. $\mathrm{Ni}$ and $\mathrm{Co}$ ions were constantly migrating to stabilize the structural instability, and the disordered phase formed by cation migration results in abnormal behaviour.

Therefore, maintenance of TM-O bonding and immobilization of TM ion in D-MNC, especially $\mathrm{Mn}-\mathrm{O}$ bonding and $\mathrm{Ni} / \mathrm{Co}$ ion, is expected to highly affect the stable TM redox activity and the suppression of voltage decay during cycling, unlike in OH-MNC with ordered structure.

How atomic arrangement affect structure stability of Li-excess material. Based on the multilateral analysis results, we described oxygen-centred macroscopic structure models of $\mathrm{OH}-\mathrm{MNC}$ and D-MNC with three types of de-lithiated $\mathrm{M}_{6} \mathrm{O}$ octahedron $\left(\mathrm{M}_{4} \mathrm{O}\right)$ to explain the fundamental reason for the difference in oxygen stability and structural reversibility according to atomic arrangement (Fig. 6a). Each $\mathrm{O}^{2-}$ ion is coordinated by four cations and two lithium vacancies $\left(\mathrm{V}_{\mathrm{Li}}\right)$ with different portion of $\mathrm{Li}^{+}$and transition-metal in TM and $\mathrm{Li}$ layer. $2 \mathrm{TM}-\mathrm{O}-2 \mathrm{Li}\left[2 \mathrm{~V}_{\mathrm{Li}}\right]$, $3 \mathrm{TM}-\mathrm{O}-1 \mathrm{Li}\left[2 \mathrm{~V}_{\mathrm{Li}}\right]$ and $4 \mathrm{TM}-\mathrm{O}-0 \mathrm{Li}\left[2 \mathrm{~V}_{\mathrm{Li}}\right]$ models represent the base structures of de-lithiated $C 2 / m, R \overline{3} \mathrm{~m}$, and cation-disordered $R \overline{3} m$, respectively (Fig. 6a). High number of TM around oxygen increases the $\mathrm{O} 2 p$-TM $3 d t_{2 \mathrm{~g}}$ orbital hybridization and decreases the possibility of holes localization on the oxygen sites at charged states compare to high number of $\mathrm{Li}$ around oxygen ${ }^{28,29}$.

Microscopic structural analysis along $[310]_{\text {mono }}$ and $[100]_{\text {mono }}$ directions and EXAFS spectra revealed that O-MNC with a wellordered structure has long-range ordering of 2TM-O-4Li octahedron. In contrast, $2 \mathrm{TM}-\mathrm{O}-4 \mathrm{Li}$ ordering is broken in D$\mathrm{MNC}$ because the disordered cations in the Li layer form 3TM-O$3 \mathrm{Li}$ and $4 \mathrm{TM}-\mathrm{O}-2 \mathrm{Li}$ octahedrons in the $[100]_{\text {mono }}$ structure (Supplementary Fig. 23). At de-lithiated state, the presence of $4 \mathrm{TM}-\mathrm{O}-0 \mathrm{Li}\left[2 \mathrm{~V}_{\mathrm{Li}}\right]$ octahedrons in structure increases the number of stable oxygen and possibility of hole delocalization on oxygen related with high covalency of TM-O bonding and low oxidation number in D-MNC. In perspective of cation, stable oxygen resulting from short-range ordered $2 \mathrm{TM}-\mathrm{O}-2 \mathrm{Li}\left[2 \mathrm{~V}_{\mathrm{Li}}\right]$ octahedron is coordinated around the TM of D-MNC unlike in $\mathrm{OH}-$ MNC (Fig. 6b). High-voltage condition causes excessive oxidation of TM in the structure, resulting in more oxygen loss on TM-O bonding, especially $\mathrm{Mn}^{3.65+}-\mathrm{O}$ bonding (less covalent) compared to $\mathrm{Ni}^{3.08+} / \mathrm{Co}^{2.98+}-\mathrm{O}$ bonding. When charge compensation is continuously repeated, series of oxygen loss occurs from overall TM-O bonding, and $\mathrm{Ni} / \mathrm{Co}$ cation migration is preferentially occurred in the ordered structure of $\mathrm{OH}-\mathrm{MNC}$ than in the cationdisordered structure of D-MNC (Fig. 6c).

\section{Discussion}

Structural arrangement with de-lithiated oxygen-centred octahedron $\left(\mathrm{M}_{4} \mathrm{O}\right)$ and interactions between those octahedrons are important reasons for Li-excess material degradation. By combining spectroscopy and microscopy techniques, we reveal that the cation distribution in $\mathrm{Li}$ and $\mathrm{TM}$ layers determines the ordering of octahedron $\left(\mathrm{M}_{6} \mathrm{O}\right)$ and different TM-O bonding covalency. At charged state, numbers of labile oxygen (high possibility of hole localization) arisen from excess oxidation of 
a
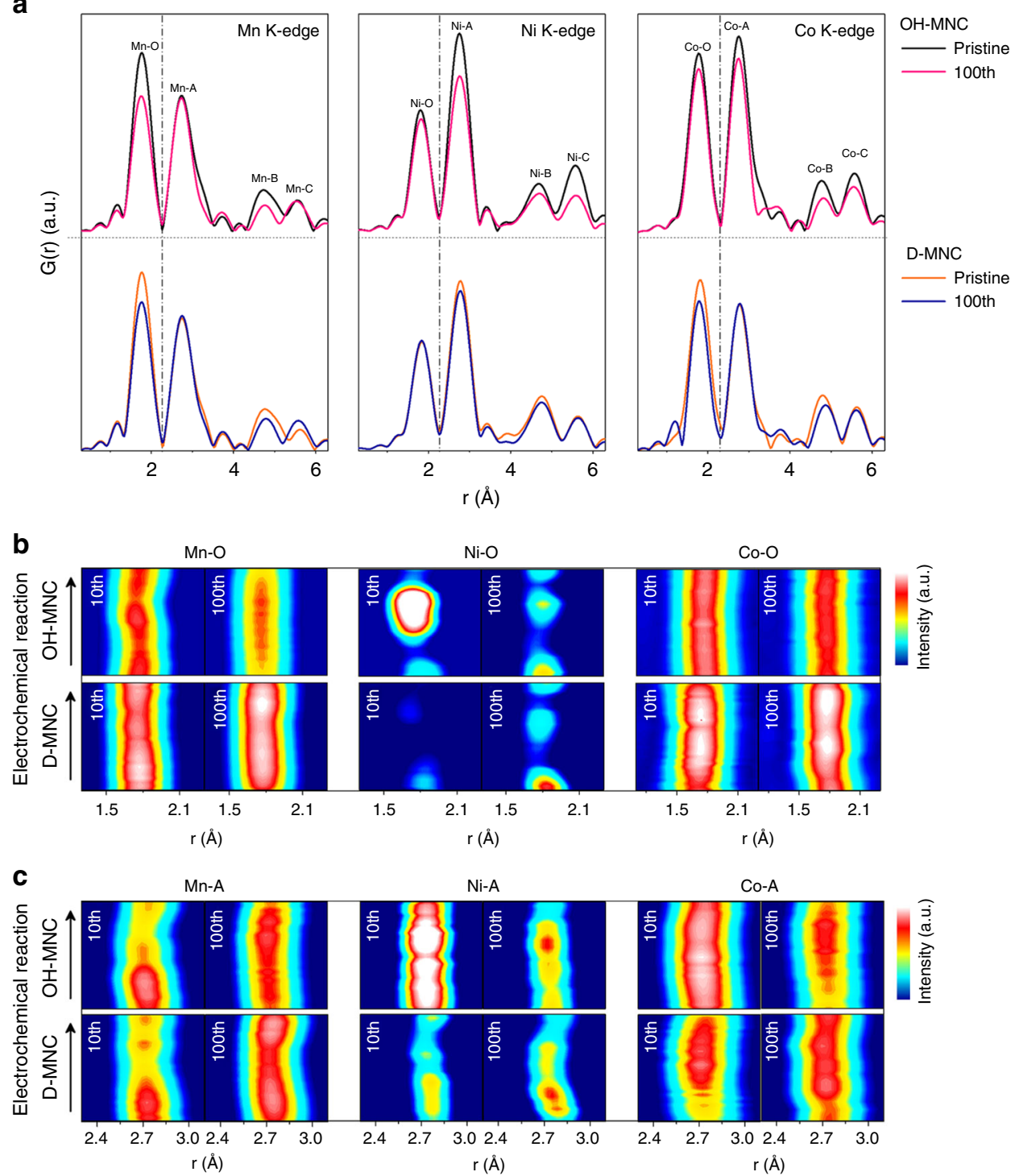

Fig. 5 Migration of specific elements due to the structural instability. a Radial distribution function (RDF) of Mn, Ni, and Co K-edges $k^{3}$-weighted EXAFS spectra for pristine and 100th cycled (discharged state) electrode of OH-MNC and D-MNC; Comparison of OH-MNC and D-MNC K-edge operando EXAFS spectra (2D contour plot) collected during 10th and 100th cycle. Spectra represents $\mathbf{b}$ TM-O peak and $\mathbf{c}$ TM-A peak variation of Mn, Ni, and Co K-edges

well-ordered $\mathrm{Li}_{2} \mathrm{TMO}_{3}$ phase leads to decrease of TM-O bonding covalency, especially $\mathrm{Mn}-\mathrm{O}$ bonding, resulting in oxygen loss from lattice and irreversibility of the overall TM-O bonding. In particularly, Ni/Co ions surrounded with labile oxygens and oxygen vacancies significantly migrate into $\mathrm{Li}$ vacancies, and consequently causes 'layered to $\mathrm{TM}_{3} \mathrm{O}_{4}$ ' phase transition during the cycling. These features finally bring about the inactive-redox and active-redox reaction in $\mathrm{Ni} / \mathrm{Co}$ and $\mathrm{Mn}$, respectively, causing the voltage decay phenomenon. By comparing ordered and cation-disordered Li-excess 3dTM material, we advance the basic understanding of voltage decay phenomenon, in terms of delithiated oxygen-centred octahedron $\left(\mathrm{M}_{4} \mathrm{O}\right)$, and propose candidate structure model to suppress voltage decay, having partially distributed cation-disordered site, not a well-ordered structure.

\section{Methods}

Sample preparation. $\mathrm{Li}_{1.15} \mathrm{Mn}_{0.51} \mathrm{Co}_{0.17} \mathrm{Ni}_{0.17} \mathrm{O}_{2}$ (denoted as $\mathrm{O}-\mathrm{MNC}$ ) and $\mathrm{Li}_{1.09} \mathrm{Mn}_{0.55} \mathrm{Ni}_{0.32} \mathrm{Co}_{0.043} \mathrm{O}_{2}$ (denoted as $\mathrm{D}-\mathrm{MNC}$ ), were prepared by coprecipitation method. Stoichiometric amounts of $\mathrm{MnSO}_{4} \cdot 5 \mathrm{H}_{2} \mathrm{O}(99.0 \%$, JUNSEI), $\mathrm{NiSO}_{4} \cdot 6 \mathrm{H}_{2} \mathrm{O}\left(98.5 \sim 102 \%\right.$, SAMCHUN) and $\mathrm{CoSO}_{4} \cdot 7 \mathrm{H}_{2} \mathrm{O}(98.0 \%$, SAMCHUN) were used as the starting materials. An aqueous solution of the reagents at a concentration of $3.0 \mathrm{~mol} \mathrm{~L}^{-1}$ was pumped into a continuously stirred tank reactor (CSTR; $4 \mathrm{~L}$ ) under a nitrogen atmosphere. The $\mathrm{pH}$ was adjusted to 10.5 with a 3.0 mol L ${ }^{-1}$ solution of $\mathrm{NaOH}$, and a desired amount of a solution of $\mathrm{NH}_{4} \mathrm{OH}(4 \mathrm{~mol}$ $\mathrm{L}^{-1}$ ) as a chelating agent was also separately fed into the reactor. The obtained solid was filtered, washed many times with distilled water, and then dried at $110^{\circ} \mathrm{C}$ for $12 \mathrm{~h}$. The dried powder was thoroughly mixed with $\mathrm{LiOH} \cdot \mathrm{H}_{2} \mathrm{O}$. (98.0\%, SigmaAldrich) and calcined at $900{ }^{\circ} \mathrm{C}$ for $10 \mathrm{~h}$. To analyze the material characteristics, pristines and electrodes recovered in the discharged state at $\sim 2.00 \mathrm{~V}$ after 10 and 100 cycles, respectively,

Transmission electron microscopy (TEM) analysis. Structural characterization of the samples was carried out using SEM (Verios 460, FEI). HR-TEM (JEM-2100F, FEI) was conducted for detailed analysis. EDS was utilized in HR-TEM (EDS, Aztec, Oxford). XRD (D/Max2000, Rigaku) was carried out for the powder analysis using $\mathrm{Cu}-\mathrm{Ka}$ radiation, a scan range of $10-90^{\circ}$, a step size of $0.005^{\circ}$, and a counting time of $5 \mathrm{~min}$. Rietveld profile refinements were performed using the GSAS suite of programs. HAADF-STEM images were obtained with aberration-corrected JEM$2100 \mathrm{~F}$ electron microscopes operated at $160 \mathrm{kV}$ using a convergence semi-angle of $22 \mathrm{mrad}$. The HAADF inner and outer collection semi-angle was $54 \mathrm{mrad}$ and 220 mrad, respectively. Simulated HAADF/ABF-STEM image and FFT pattern were obtained by using Dr.probe ${ }^{46}$ and CrysTbox ${ }^{47}$ program.

Operando X-ray absorption spectroscopy (XAS). Operando transition metal $(\mathrm{TM}=\mathrm{Mn}, \mathrm{Ni}, \mathrm{Co}) \mathrm{K}$-edge X-ray absorption fine structure (XAFS), X-ray 


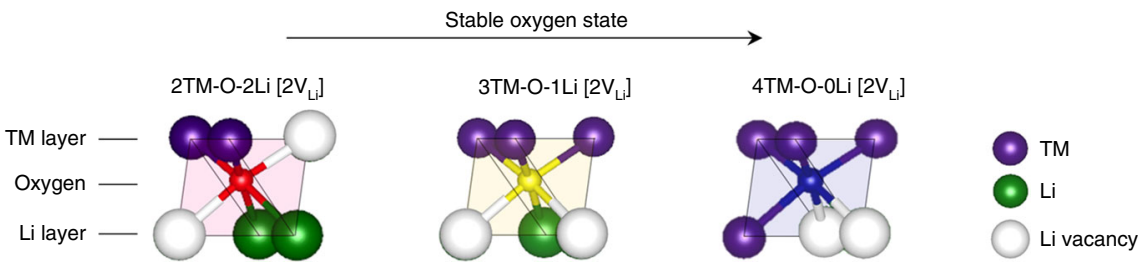

b

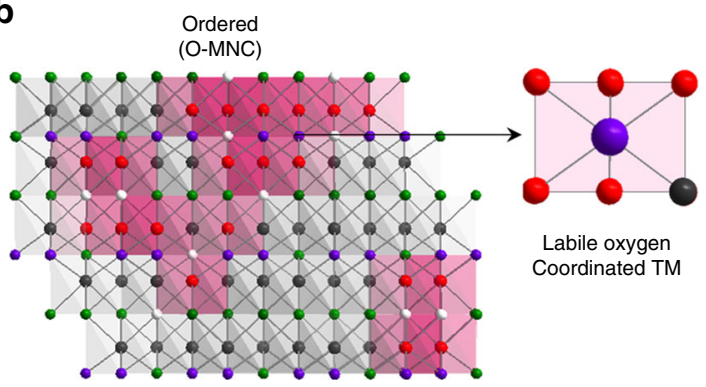

Cation-disordered (D-MNC)

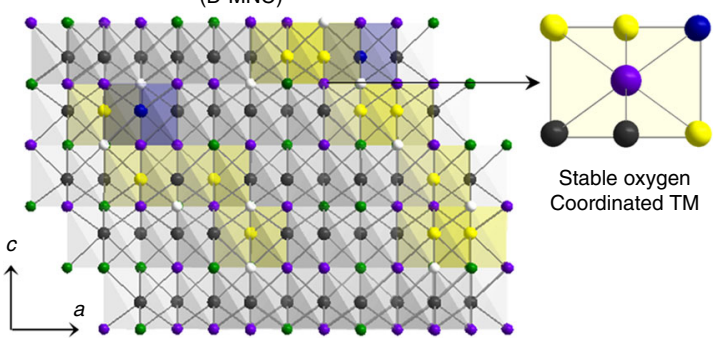

C

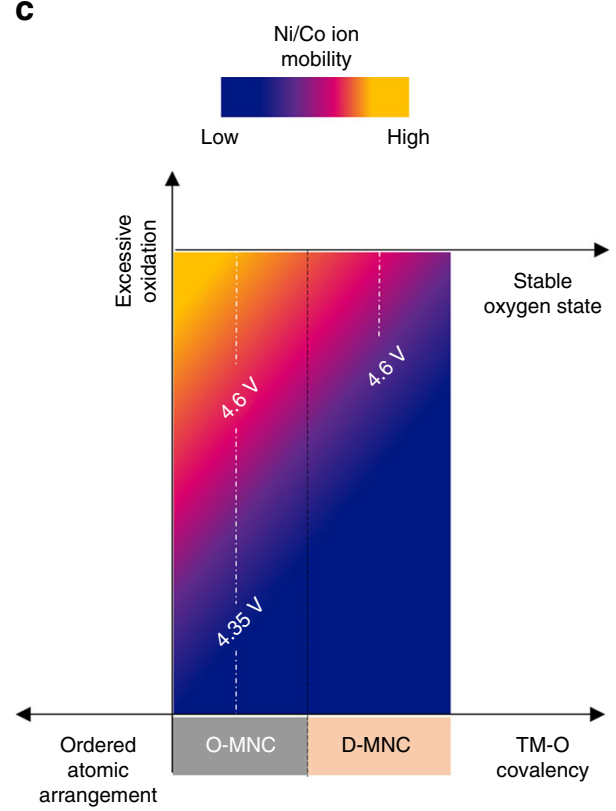

Fig. 6 Factors to consider in interpreting the structural stability of high capacity cathode material. a Three de-lithiated oxygen-centred octahedron ( $\mathrm{M}_{4} \mathrm{O}$ ) of $\mathrm{Li}$-excess material. Each oxygen anions coordinated by four cations and two lithium vacancies $\left(\mathrm{V}_{\mathrm{Li}}\right)$ with different portion of $\mathrm{Li}^{+}$and transition-metal in $\mathrm{TM}$ and $\mathrm{Li}$ layer. $2 \mathrm{TM}-\mathrm{O}-2 \mathrm{Li}\left[2 \mathrm{~V}_{\mathrm{Li}}\right], 3 \mathrm{TM}-\mathrm{O}-1 \mathrm{Li}\left[2 \mathrm{~V}_{\mathrm{Li}}\right]$ and $4 \mathrm{TM}-\mathrm{O}-\mathrm{OLi}\left[2 \mathrm{~V}_{\mathrm{Li}}\right]$ octahedron represent the base structure of de-lithiated $\mathrm{Li}_{2} \mathrm{TMO}_{3}, \mathrm{LiTMO}_{2}$ and cation-disordered-LiTMO $\mathrm{M}_{2}$ and the degree of stability on centred oxygen represented as different color (Red is highly labile). $\mathbf{b}$ Oxygen-centred macroscopic structure model of de-lithiated state $\mathrm{OH}-\mathrm{MNC}$ and D-MNC along $[100]_{\text {mono. }}$ c Schematic of structure stability according to the material characteristics and electrochemical conditions

absorption near edge structure (XANES) and extended X-ray absorption fine structure (EXAFS), were collected on the BL10C beam line (WEXAFS) at the Pohang light source (PLS-II) with top-up mode operation under a ring current of $360 \mathrm{~mA}$ at $3.0 \mathrm{GeV}$. From the high-intensity X-ray photons of the multipole wiggler source, monochromatic X-ray beams could be obtained using a liquidnitrogen-cooled double-crystal monochromator (Bruker ASC) with available in situ exchange in vacuum between a $\mathrm{Si}(111)$ and $\mathrm{Si}(311)$ crystal pair. The $\mathrm{Si}(111)$ crystal pair was used for TM K-edge XAFS measurements. Real-time TM K-edge X-ray absorption spectroscopic data during discharging and charging processes were recorded for 10th-cycled OL-MNC, 10th/100th-cycled OH-MNC, and 10th/100thcycled D-MNC electrodes assembled in a home-made in situ electrochemical cell with polyimide film windows (Swagelok-type cell), in transmittance mode using $\mathrm{N}_{2}$ gas-filled ionization chambers (IC-SPEC, FMB Oxford) for the incident and transmitted X-ray photons. Higher-order harmonic contaminations were eliminated by detuning to reduce the incident X-ray intensity by $\sim 30 \%$. Energy calibration was simultaneously carried out for each measurement with reference TM foils placed in front of the third ion chamber. All XAFS data were measured using on-the-fly mode with scanning time of $1 \mathrm{~min}$ for one spectrum per every $5 \mathrm{~min}$. Under the $0.5 \mathrm{C}$-rate charging and 1C-rate discharging, XAFS spectra above 20 scans in charging and above 10 scans in discharging have been acquired independently for all electrodes. The data reductions of the experimental spectra to normalized XANES and Fourier-transformed radial distribution functions (RDFs) were performed through the standard XAFS procedure. Using AUTOBK and FEFFIT modules in UWXAFS package, the $k^{3}$-weighted TM K-edge EXAFS spectra, $k^{3} \chi(k)$, have been obtained through background removal and normalization processes on the edge jump. In order to present effective radial distribution functions (RDF) for each sample during charge-discharge, the $k^{3} \chi(k)$ spectra have been Fourier-transformed (FT) in the $k$ range between 2.5 and $12.0 \AA^{-1}$.

Scanning transmission X-ray microscopy (STXM). STXM images and Soft X-ray absorption spectroscopy (SXAS) data were obtained at the Pohang Light Source
(10A beam line) using the monochromatic soft X-rays of the synchrotron source. To obtain XAS spectra at the O K-edge, stacks of STXM images were obtained by changing the incident photon energy, while keeping the focal position at the sample plane, and then spectroscopic data from a specific point or area (in the lateral plane) were collected from the stack images through the aXis2000 software package. A monochromator resolution of $0.1 \mathrm{eV}$ was used for recording SXAS spectra. Image stacks were acquired at $520-560 \mathrm{eV}$ (O K-edge) to extract the X-ray absorption spectra from the surface region of samples.

Electrochemical characterization. For fabrication of the cathode electrode, the prepared powders were mixed with carbon black and polyvinylidene fluoride (8:1:1) in N-methylpyrrolidinon. The obtained slurry was casted onto $\mathrm{Al}$ foil with active material loaded at $4.5-5.0 \mathrm{mg} \mathrm{cm}^{-2}$ and roll-pressed. The electrodes were dried overnight at $110^{\circ} \mathrm{C}$ in dry oven. The electrochemical performances of the prepared O-MNC and D-MNC were measured in tests using 2032 coin-type cells. The coin cells were assembled with Li metal as the counter and reference electrodes. In order to assemble the cell, CR2032 (half-cell) cell were utilized in argonfilled glove box. The electrolyte was a solution of $1.3 \mathrm{M} \mathrm{LiPF}_{6}$ in ethylene carbonate (EC)/ethylmethyl carbonate (EMC)/ diethyl carbonate (DEC)/(2/5/3, by volume) with $5.0 \%$ of fluoroethylene carbonate, $0.5 \%$ of vinylene carbonate and $1.0 \%$ of tris (trimethylsilyl) phosphite. As a separator, microporous polyethylene (Celgard) was used. The galvanostatic charge-discharge cycling was carried out between 2.0 and $4.6 \mathrm{~V}\left(\mathrm{vs} . \mathrm{Li} / \mathrm{Li}^{+}\right)$at $25^{\circ} \mathrm{C}$ temperature. To obtain accurate data, 4 cells per sample were tested.

Data availability. The authors declare that the data supporting the findings of this study are available within the article and its Supplementary Information Files. All other relevant data supporting the findings of this study are available on request. 
Received: 11 April 2018 Accepted: 31 July 2018

Published online: 16 August 2018

\section{References}

1. Goodenough, J. B. \& Kim, Y. Challenges for rechargeable Li batteries. Chem. Mater. 22, 587-603 (2010).

2. Whittingham, M. S. Lithium batteries and cathode materials. Chem. Rev. 104, 4271-4301 (2004).

3. Palacín, M. R. Recent advances in rechargeable battery materials: a chemist's perspective. Chem. Soc. Rev. 38, 2565-2575 (2009).

4. Thackeray, M. M. et al. $\mathrm{Li}_{2} \mathrm{MnO}_{3}$-stabilized $\mathrm{LiMO}_{2}(\mathrm{M}=\mathrm{Mn}, \mathrm{Ni}, \mathrm{Co})$ electrodes for lithium-ion batteries. J. Mater. Chem. 17, 3112-3125 (2007).

5. Zhou, F., Zhao, X., Van Bommel, A., Xia, X. \& Dahn, J. R. Comparison of Li $\left[\mathrm{Li}_{1 / 9} \mathrm{Ni}_{1 / 3} \mathrm{Mn}_{5 / 9}\right] \mathrm{O}_{2}$, $\mathrm{Li}\left[\mathrm{Li}_{1 / 5} \mathrm{Ni}_{1 / 5} \mathrm{Mn}_{3 / 5}\right] \mathrm{O}_{2}, \mathrm{LiNi}_{0.5} \mathrm{Mn}_{1.5} \mathrm{O}_{4}$, and $\mathrm{LiNi}_{2 / 3} \mathrm{Mn}_{1 /}$ ${ }_{3} \mathrm{O}_{2}$ as high voltage positive electrode materials. J. Electrochem. Soc. 158, A187-A191 (2011)

6. Zheng J., et al. Li- and Mn-rich cathode materials: challenges to commercialization. Adv. Energy. Mater. 7, 1601284 (2017).

7. Bettge, M. et al. Voltage fade of layered oxides: Its measurement and impact on energy density. J. Electrochem. Soc. 160, A2046-A2055 (2013).

8. Croy, J. R., Gallagher, K. G., Balasubramanian, M., Long, B. R. \& Thackeray, M. M. Quantifying hysteresis and voltage fade in $\mathrm{xLi}_{2} \mathrm{MnO}_{3} \cdot(1-\mathrm{x})$ $\mathrm{LiMn}_{0.5} \mathrm{Ni}_{0.5} \mathrm{O}_{2}$ electrodes as a function of $\mathrm{Li}_{2} \mathrm{MnO}_{3}$ content. J. Electrochem. Soc. 161, A318-A325 (2013).

9. Gallagher, K. G. et al. Correlating hysteresis and voltage fade in lithium- and manganese-rich layered transition-metal oxide electrodes. Electrochem. Commun. 33, 96-98 (2013).

10. Croy, J. R. et al. Countering the voltage decay in high capacity $\mathrm{xLi}_{2} \mathrm{MnO}_{3} \bullet$ (1x) $\mathrm{LiMO}_{2}$ electrodes $(\mathrm{M}=\mathrm{Mn}, \mathrm{Ni}, \mathrm{Co})$ for $\mathrm{Li}^{+}$ion batteries. J. Electrochem. Soc. 159, A781-A790 (2012).

11. Yu X. Q., et al. Understanding the rate capability of high-energy-density lirich layered $\mathrm{Li}_{1.2} \mathrm{Ni}_{0.15} \mathrm{Co}_{0.1} \mathrm{Mn}_{0.55} \mathrm{O}_{2}$ cathode materials. Adv. Energy. Mater. 4 , 1300950 (2014).

12. Shimoda, K. et al. Direct observation of layered-to-spinel phase transformation in $\mathrm{Li}_{2} \mathrm{MnO}_{3}$ and the spinel structure stabilised after the activation process. J. Mater. Chem. A 5, 6695-6707 (2017).

13. Shi, J. L. et al. Mitigating voltage decay of Li-rich cathode material via increasing Ni content for lithium-ion batteries. ACS Appl. Mater. Interfaces $\mathbf{8}$, 20138-20146 (2016).

14. Shi J.-L., et al. Improving the structural stability of Li-rich cathode materials via reservation of cations in the Li-slab for Li-ion batteries. Nano Res. 10, 45201-4209 (2017).

15. Oh P., Ko M., Myeong S., Kim Y., Cho J. A novel surface treatment method and new insight into discharge voltage deterioration for high-performance $0.4 \mathrm{Li}_{2} \mathrm{MnO}_{3}-0.6 \mathrm{LiNi}_{1 / 3} \mathrm{Co}_{1 / 3} \mathrm{Mn}_{1 / 3} \mathrm{O}_{2}$ cathode materials. Adv. Energy. Mater. 4, 1400631 (2014).

16. Yan, P. et al. Evolution of lattice structure and chemical composition of the surface reconstruction layer in $\mathrm{Li}_{1.2} \mathrm{Ni}_{0.2} \mathrm{Mn}_{0.6} \mathrm{O}_{2}$ cathode material for lithium ion batteries. Nano. Lett. 15, 514-522 (2015)

17. $\mathrm{Gu}, \mathrm{M}$. et al. Formation of the spinel phase in the layered composite cathode used in Li-ion batteries. ACS Nano 7, 760-767 (2013).

18. Zheng, J. et al. Corrosion/fragmentation of layered composite cathode and related capacity/voltage fading during cycling process. Nano. Lett. 13, 3824-3830 (2013).

19. Xu, B., Fell, C. R., Chi, M. F. \& Meng, Y. S. Identifying surface structural changes in layered Li-excess nickel manganese oxides in high voltage lithium ion batteries: a joint experimental and theoretical study. Energy Environ. Sci. 4, 2223-2233 (2011).

20. Mohanty, D. et al. Investigating phase transformation in the $\mathrm{Li}_{1.2} \mathrm{Co}_{0.1} \mathrm{Mn}_{0.55} \mathrm{Ni}_{0.15} \mathrm{O}_{2}$ lithium-ion battery cathode during high-voltage hold $(4.5 \mathrm{~V})$ via magnetic, $\mathrm{X}$-ray diffraction and electron microscopy studies. J. Mater. Chem. A 1, 6249-6261 (2013).

21. $\mathrm{Wu}, \mathrm{Y}$. et al. Probing the initiation of voltage decay in Li-rich layered cathode materials at the atomic scale. J. Mater. Chem. A 3, 5385-5391 (2015).

22. Hong, J. et al. Structural evolution of layered $\mathrm{Li}_{1.2} \mathrm{Ni}_{0.2} \mathrm{Mn}_{0.6} \mathrm{O}_{2}$ upon electrochemical cycling in a Li rechargeable battery. J. Mater. Chem. 20, 10179-10186 (2010).

23. Liu W. D., et al. Countering voltage decay and capacity fading of lithium-rich cathode material at $60{ }^{\circ} \mathrm{C}$ by hybrid surface protection layers. Adv. Energy. Mater. 5, 1500274 (2015).

24. Yan, P. et al. Probing the degradation mechanism of $\mathrm{Li}_{2} \mathrm{MnO}_{3}$ cathode for $\mathrm{Li}-$ ion batteries. Chem. Mater. 27, 975-982 (2015).
25. Jarvis, K. A., Wang, C.-C., Manthiram, A. \& Ferreira, P. J. The role of composition in the atomic structure, oxygen loss, and capacity of layered Li-Mn-Ni oxide cathodes. J. Mater. Chem. A 2, 1353-1362 (2014).

26. Sathiya, M. et al. Origin of voltage decay in high-capacity layered oxide electrodes. Nat. Mater. 14, 230-238 (2015).

27. Goodenough, J. B. Perspective on engineering transition-metal oxides. Chem. Mater. 26, 820-829 (2014).

28. Luo, K. et al. Charge-compensation in $3 d$-transition-metal-oxide intercalation cathodes through the generation of localized electron holes on oxygen. Nat. Chem. 8, 684-691 (2016).

29. Seo, D. H. et al. The structural and chemical origin of the oxygen redox activity in layered and cation-disordered Li-excess cathode materials. Nat. Chem. 8, 692-697 (2016).

30. Luo, K. et al. Anion redox chemistry in the cobalt free $3 \mathrm{~d}$ transition metal oxide intercalation electrode $\mathrm{Li}\left[\mathrm{Li}_{0.2} \mathrm{Ni}_{0.2} \mathrm{Mn}_{0.6}\right] \mathrm{O}_{2}$. J. Am. Chem. Soc. 138, 11211-11218 (2016)

31. Kiss, A. M. et al. In-situ observation of nickel oxidation using synchrotron based full-field transmission X-ray microscopy. Appl. Phys. Lett. 102, 053902 (2013).

32. Simonin, L. et al. In situ investigations of a Li-rich $\mathrm{Mn}-\mathrm{Ni}$ layered oxide for Liion batteries. J. Mater. Chem. 22, 11316-11322 (2012).

33. Oishi, M. et al. Charge compensation mechanisms in $\mathrm{Li}_{1.16} \mathrm{Ni}_{0.15} \mathrm{Co}_{0.19} \mathrm{Mn}_{0.50} \mathrm{O}_{2}$ positive electrode material for Li-ion batteries analyzed by a combination of hard and soft X-ray absorption near edge structure. J. Power Sources 222, 45-51 (2013).

34. Oishi, M. et al. Direct observation of reversible oxygen anion redox reaction in Li-rich manganese oxide, $\mathrm{Li}_{2} \mathrm{MnO}_{3}$, studied by soft X-ray absorption spectroscopy. J. Mater. Chem. A 4, 9293-9302 (2016).

35. Yan, W. et al. Oxygen vacancy effect on room-temperature ferromagnetism of rutile $\mathrm{Co:} \mathrm{TiO}_{2}$ thin films. Appl. Phys. Lett. 94, (042508 (2009).

36. Genevois, C. et al. Insight into the atomic structure of cycled lithium-rich layered oxide $\mathrm{Li}_{1.20} \mathrm{Mn}_{0.54} \mathrm{Co}_{0.13} \mathrm{Ni}_{0.13} \mathrm{O}_{2}$ using HAADF STEM and electron nanodiffraction. J. Mater. Chem. C. 119, 75-83 (2015).

37. Yu, H. et al. Crystalline grain interior configuration affects lithium migration kinetics in Li-Rich layered oxide. Nano. Lett. 16, 2907-2915 (2016).

38. Bareno, J. et al. Local structure of layered oxide electrode materials for lithium-ion batteries. Adv. Mater. 22, 1122-1127 (2010).

39. Boulineau, A. et al. Evolutions of $\mathrm{Li}_{1.2} \mathrm{Mn}_{0.61} \mathrm{Ni}_{0.18} \mathrm{Mg}_{0.01} \mathrm{O}_{2}$ during the initial charge/discharge cycle studied by advanced electron microscopy. Chem. Mater. 24, 3558-3566 (2012).

40. Jarvis, K. A., Deng, Z., Allard, L. F., Manthiram, A. \& Ferreira, P. J. Atomic structure of a lithium-rich layered oxide material for lithium-ion batteries: evidence of a solid solution. Chem. Mater. 23, 3614-3621 (2011).

41. Jarvis, K. A., Deng, Z., Allard, L. F., Manthiram, A. \& Ferreira, P. J. Understanding structural defects in lithium-rich layered oxide cathodes. $J$. Mater. Chem. 22, 11550 (2012).

42. Rana, J. et al. On the structural integrity and electrochemical activity of a $0.5 \mathrm{Li}_{2} \mathrm{MnO}_{3} \cdot 0.5 \mathrm{LiCoO}_{2}$ cathode material for lithium-ion batteries. J. Mater. Chem. A 2, 9099-9110 (2014).

43. Croguennec, L., Pouillerie, C. \& Delmas, C. $\mathrm{NiO}_{2}$ obtained by electrochemical lithium deintercalation from lithium nickelate: structural modifications. $J$. Electrochem. Soc. 147, 1314-1321 (2000).

44. Croguennec, L., Pouillerie, C., Mansour, A. N. \& Delmas, C. Structural characterisation of the highly deintercalated $\mathrm{Li}_{\mathrm{x}} \mathrm{Ni}_{1.02} \mathrm{O}_{2}$ phases (with $\mathrm{x} \leq$ 0.30). J. Mater. Chem. 11, 131-141 (2001).

45. Yin, S. C., Rho, Y. H., Swainson, I. \& Nazar, L. F. X-ray/neutron diffraction and electrochemical studies of lithium De/Re-intercalation in $\mathrm{Li}_{1-\mathrm{x}} \mathrm{Co}_{1 / 3} \mathrm{Ni}_{1 /}$ ${ }_{3} \mathrm{Mn}_{1 / 3} \mathrm{O}_{2}(\mathrm{x}=0 \rightarrow 1)$. Chem. Mater. 18, 1901-1910 (2006).

46. Barthel, J. Dr. Probe: A software for high-resolution STEM image simulation Ultramicroscopy 193, 1-11 (2018).

47. Klinger, M. More features, more tools, more CrysTBox. J. Appl. Crystallogr. 50, 1226-1234 (2017).

\section{Acknowledgements}

This work was supported by IT R\&D program of MOTIE/KEIT (Development of Li-rich Cathode and Carbon-free Anode Materials for High Capacity/High Rate Lithium Secondary Batteries, 10046309). Also, Research Funds (1.180019.01 and 1.180033.01) and of Ulsan National Institute of Science and Technology (UNIST) was greatly acknowledged.

\section{Author contributions}

S.M. conceived and designed the experiments. S.M. performed and analyzed the major part of the experiments and the results; W.C., W.J. and J-G.H. assisted with sample preparation and electrochemical test; M.Y assisted with XRD analysis. G.N and H.J assisted with XAS measurement. J.H and N-S.C offered electrolyte; Y.Y. assisted with 
TEM analysis. M.G.K assisted with XAS analysis. S.M. wrote the paper. W.C., M.G.K., and J.C., discussed the results and revised or commented the manuscript.

\section{Additional information}

Supplementary Information accompanies this paper at https://doi.org/10.1038/s41467018-05802-4

Competing interests: The authors declare no competing interests.

Reprints and permission information is available online at http://npg.nature.com/ reprintsandpermissions/

Publisher's note: Springer Nature remains neutral with regard to jurisdictional claims in published maps and institutional affiliations. (c) (i) Open Access This article is licensed under a Creative Commons Attribution 4.0 International License, which permits use, sharing, adaptation, distribution and reproduction in any medium or format, as long as you give appropriate credit to the original author(s) and the source, provide a link to the Creative Commons license, and indicate if changes were made. The images or other third party material in this article are included in the article's Creative Commons license, unless indicated otherwise in a credit line to the material. If material is not included in the article's Creative Commons license and your intended use is not permitted by statutory regulation or exceeds the permitted use, you will need to obtain permission directly from the copyright holder. To view a copy of this license, visit http://creativecommons.org/ licenses/by/4.0/.

(C) The Author(s) 2018 